David C. Campbell MD, M. Joanne Douglas FRCP, Timothy J.G. Pavy fFarcs, Pamela Merrick BSN, Mary Lou Flanagan FRCP, Graham H. McMorland FRCP

\title{
Comparison of the 25-gauge Whitacre with the 24-gauge Sprotte spinal needle for elective Caesarean section: cost implications
}

Spinal anaesthesia provides rapid, safe anaesthesia for Caesarean section. The pencil-point spinal needles (Sprotte and Whitacre) are reported to have a low incidence of post-dural puncture headache (PDPH). As the 25G Whitacre is less expensive than the $24 G$ Sprotte needle, this prospective, randomized, doubleblind study was designed to compare the incidence of PDPH and ease of insertion of these needles in 304 ASA 1 and 2 women having elective Caesarean section under spinal anaesthesia. Each patient was assessed daily for five consecutive days following Caesarean section by an investigator blinded to the needle used. The results indicate that the two needles have a similar ease of insertion, number of failed insertions, and failed subarachnoid blockade. An inability to insert the spinal needles occurred in two patients in each group. Therefore, 150 patients in each group completed the study. The incidence of PDPH with the 24G Sprotte needle was $4.0 \%$ (6/150) compared with $0.66 \%$ (1/150) with the $25 \mathrm{G}$ Whitacre (NS). There was no cor-

Key words

ANAESTHESIA: obstetric;

ANAESTHETIC TECHNIQUES: spinal;

COMPLICATIONS: headache, inadequate block.

From the Department of Anaesthesia, Faculty of Medicine, University of British Columbia, Grace Hospital, 4490 Oak

Street, Vancouver, British Columbia, Canada V6H 3V5.

This study was completed at the Grace Hospital, University of British Columbia, Vancouver, British Columbia.

The results were presented at the annual meeting of the Canadian Anaesthetists' Society, June 5-9, 1992.

Address correspondence to: Dr. Douglas, Department of Anaesthesia, Grace Hospital, 4490 Oak Street, Vancouver, B.C. V6H 3V5.

Accepted for publication 16th August, 1993. relation between the occurrence of PDPH and the difficulty of needle insertion, presence of transient hypotension or the effectiveness of anaesthesia delivered. This study indicates that both needles are comparable with respect to ease of insertion and incidence of PDPH. As the Whitacre needle is less expensive it is a reasonable alternative to the more expensive Sprotte needle.

La rachianesthésie administrée pour la césarienne offre les avantages d'une installation rapide et d'une grande sécurité. Lincidence de la céphalée post-rachidienne avec l'utilisation d'aiguilles à extrémité conique (Sprotte et Whitacre) est faible. Toutefois, l'aiguille Whitacre $25 G$ coûte moins cher que la Sprotte 24G. Cette étude randomisée, prospective et à double insu vise à comparer pour ces deux aiguilles lincidence de céphalée post-rachidienne et leur facilité d'insertion chez 304 parturientes $A S A 1$ et 2 programmées pour césarienne non urgente sous rachianesthésie. Après lintervention, chaque patiente est évaluée pendant cinq jours consécutifs par un observateur ignorant du type d'aiguille utilisé. Les résultats montrent que les deux aiguilles sïntroduisent avec la même facilité; la fréquence des insertions impossibles et des anesthésies ratées est la même pour les deux aiguilles. L'impossibilité d'insérer laiguille rachidienne survient deux fois dans chaque groupe. Cent cinquante patientes de chaque groupe ont donc pu compléter l'étude. Lincidence de céphalée post-rachidienne avec l'aiguille Sprotte $24 G$ est de 4,0\% (6/150) comparativement $\dot{a}$ $0,66 \%$ (1/150) avec la Whitacre $25 G$ (NS). On ne trouve pas de corrélation entre la céphalée post-rachidienne et linsertion difficile, l'hypotension transitoire ou la qualité de l'anesthésie. Cette étude montre que les deux aiguilles sont comparables au regard de la facilité dinsertion et de lincidence de céphalée post-rachidienne. Le prix moins élevé de l'aiguille de Whitacre constitue un avantage sur l'aiguille Sprotte.

Until recently, one of the drawbacks to the use of spinal anaesthesia for Caesarean section has been the high in- 
cidence of post-dural puncture headache (PDPH) in the parturient. A resurgence in the use of spinal anaesthesia was initiated by the development of spinal needles with pencil point, non-cutting tips. In cadaveric preparations these needles reduce cerebral spinal fluid (CSF) leakage after dural puncture. ' The 24-gauge (G) Sprotte spinal needle with the pencil point, non-cutting tip was initially reported to have a PDPH incidence of $<1 \%$ in an obstetrical population. ${ }^{2}$ However, these needles are relatively expensive, a consideration in the current climate of restraint with respect to hospital costs.

Recent reports ${ }^{3.4}$ indicate that the incidence of PDPH with the $24 \mathrm{G}$ Sprotte is higher than that reported by Sprotte $e t a l^{2}$ and Cesarini $e t$ al. ${ }^{5}$ Concern has also been expressed regarding the number of failed subarachnoid blocks when using the $24 \mathrm{G}$ Sprotte spinal needle. ${ }^{6}$ The smaller $25 \mathrm{G}$ Whitacre needle, which has a similar noncutting, pencil point tip but a smaller ejection port, might have a comparable low incidence of PDPH and failed subarachnoid blockade.

Our teaching hospital began using the Sprotte needle for spinal anaesthesia for Caesarean section following the reports of a decreased incidence of PDPH. As the 25G Whitacre needle had a similar theoretical advantage but was less expensive, this prospective, randomized, doubleblind study was designed to compare the incidence of PDPH following the use of these two needles for spinal anaesthesia for elective Caesarean section. In addition, ease of insertion, effectiveness of anaesthesia, incidence of failed subarachnoid blockade and other complications were evaluated.

\section{Methods}

Following Institutional Ethics Committee approval and informed patient consent, 304 ASA 1 and 2 women undergoing spinal anaesthesia for elective Caesarean section were recruited. They were randomized, using a randomization table, ${ }^{7}$ into two groups having spinal anaesthesia performed with either the 24G Sprotte (Pajunk GmbH Medecin Technik, West Germany) or the 25G Whitacre (Becton Dickinson, Rutherford, New Jersey) spinal needle.

Following intravenous administration of two litres of a balanced salt solution the patients were positioned in the right lateral or sitting position and lumbar puncture was performed in the midline between $\mathrm{L}_{2-3}$ or $\mathrm{L}_{3-4}$. The spinal needle was introduced with the ejection orifice parallel to the dural fibres. Upon entering the subarachnoid space, as evidenced by clear, free-flowing CSF, the needle was rotated so that the ejection orifice was directed cephalad. The local anaesthetic solution was then injected. Following injection, CSF was again aspirated to confirm placement of the needle and solution in the subarachnoid space.
TABLE I Headache severity

\begin{tabular}{ll}
\hline Mild: & $\begin{array}{l}\text { No limitation of activity } \\
\text { No treatment required } \\
\text { Limited activity }\end{array}$ \\
Moderate: & $\begin{array}{l}\text { Regular analgesics required } \\
\text { Confined to bed; anorexic } \\
\text { Unable to feed baby }\end{array}$ \\
\hline
\end{tabular}

The local anaesthetic solution was hyperbaric $0.75 \%$ bupivacaine (Sterling-Winthrop) and preservative-free morphine (A.H. Robins Canada Inc.) and fentanyl (Janssen Pharmaceutica Inc.). The doses of bupivacaine, morphine and fentanyl were determined by the anaesthetist doing the procedure with a planned anaesthetic level of $T_{4}$.

All patients were blinded to the needle utilized. The anaesthetist conducting the procedure was not blinded as the two needles have a different appearance making blinding impossible. Patients were assessed after operation by an investigator blinded to the needle and not involved in their perioperative care.

The number of attempts at spinal needle insertion, dose of bupivacaine, block level and incidence of hypotension were documented. Intraoperative supplementation, as decided by the anaesthetist conducting the procedure, with either nitrous oxide and/or $i v$ fentanyl (50-100 $\mu \mathrm{g})$, was recorded. Failed subarachnoid blockade was defined as no anaesthesia or ineffective anaesthesia for surgery following injection of the local anaesthetic solution.

Post-partum, all patients, including those in whom lumbar puncture could not be performed, were assessed daily for five days by an investigator blinded to the needle utilized. If a patient was discharged early, the follow-up was conducted by a home care nurse. At the time of assessment each patient was asked about headache and, if present, its character, location, severity, duration and treatment. The severity of the headache was classified according to the criteria listed in Table I. Post-dural puncture headache was defined as a headache aggravated by upright positioning and relieved in the supine position. If the presence of PDPH was equivocal, a second independent and blinded anaesthetist evaluated the patient to determine whether the headache in question was a PDPH.

Continuous variables (age, height, weight, bupivacaine dose) were normally distributed and were analyzed using the unpaired t-test. Categorical variables were analyzed with either Chi square or Fisher's exact test, where appropriate. Data are expressed as means plus or minus the standard deviation, or as counts and percentages. $P$ $<0.05$ was considered significant. 
TABLE II Demographic data

\begin{tabular}{lcc}
\hline & $\begin{array}{l}24 \text {-gauge } \\
\text { Sprotte } \\
(n=150)\end{array}$ & $\begin{array}{l}\text { 25-gauge } \\
\text { Whitacre } \\
(n=150)\end{array}$ \\
\hline Age $(\mathrm{yr})$ & $32.0 \pm 4.7$ & $32.0 \pm 5.3$ \\
Height $(\mathrm{cm})$ & $158.8 \pm 7.5$ & $158.7 \pm 6.9$ \\
Weight $(\mathrm{kg})$ & $73.9 \pm 12.7$ & $73.5 \pm 11.4$ \\
Multiparity & $117(78 \%)$ & $121(81 \%)$ \\
Physical status: ASA I & $137(91 \%)$ & $135(90 \%)$ \\
\hline
\end{tabular}

\section{Results}

There were no differences between the two groups of patients with respect to the demographic data (Table II), ease of needle insertion, number of failed insertions, bupivacaine dose or occurrence of transient hypotension (Table III). The two groups were similar with respect to the number of patients having the block instituted in the right lateral or sitting position (Table III).

Failure to identify the subarachnoid space (lack of clear, free-flowing CSF) occurred in four patients, two with the 25G Whitacre (1.3\%) and two with the 24G Sprotte (1.3\%). Therefore 150 patients had successful lumbar puncture with each spinal needle. The four, in whom CSF was not obtained, did not develop a PDPH.

The number of patients receiving each dose per patient height of bupivacaine was not different between the two groups for each of the three dosage intervals (Table IV).

Three (2.0\%) failed subarachnoid blockades were reported with the $24 \mathrm{G}$ Sprotte and two (1.3\%) with the 25G Whitacre following successful dural puncture (NS) (Table III). All five patients had the procedure repeated, necessitating a second dural puncture. None of these patients developed a PDPH. Sixty-two (20.6\%) non-spinal headaches were reported postpartum. Of these, $25.3 \%$ $(38 / 150)$ were reported with the 24G Sprotte and $16.0 \%$ $(24 / 150)$ with the $25 \mathrm{G}$ Whitacre $(P=0.05)$. All of the non-spinal headaches were mild.

The incidence of PDPH was $4.0 \%(6 / 150)$ with the 24G Sprotte needle and $0.66 \%(1 / 150)$ with the $25 \mathrm{G}$ Whitacre (NS). Four in the Sprotte group were mild and two were severe. The one PDPH in the 25G Whitacre group was severe. One patient in each group required a blood patch.

The occurrence of PDPH and the difficulty of needle insertion were not related. All but one patient, in whom two attempts were required, had successful lumbar punctures with one attempt. Neither transient hypotension nor the effectiveness of anaesthesia delivered were related to the occurrence of PDPH.

Analgesia supplementation was required by $17.3 \%(26)$ 150 ) of the patients in the $24 \mathrm{G}$ Sprotte group compared
TABLE III Results

\begin{tabular}{lcc}
\hline & $\begin{array}{l}\text { 24-gauge } \\
\text { Sprotte } \\
(n=150)\end{array}$ & $\begin{array}{l}\text { 25-gauge } \\
\text { Whitacre } \\
(n=150)\end{array}$ \\
\hline Ease of insertion & & \\
- 1st or 2nd attempt & $135(90 \%)$ & $136(91 \%)$ \\
Position for insertion & & \\
- Right lateral & 44 & 31 \\
- Sitting & 106 & 118 \\
Bupivacaine (mg) & $9.76 \pm 0.92$ & $9.78 \pm 0.83$ \\
Transient hypotension & $69(46 \%)$ & $71(47 \%)$ \\
Effectiveness & & \\
- Supplementation required & $26(17.3 \%)^{*}$ & $5(3.3 \%)^{*}$ \\
- Failed block & $3(2.0 \%)$ & $2(1.3 \%)$ \\
Headache & & $24(16.0 \%)$ \\
- Non-spinal headache & $38(25.3 \%)$ & $1(0.66 \%)$ \\
- PDPH & $6(4.0 \%)$ & 1 \\
Blood patch & 1 &
\end{tabular}

$* P<0.0001$.

TABLE IV Patients requiring supplementation to subarachnoid blockade for each dose per patient height interval of bupivacaine

\begin{tabular}{lll}
\hline Bupivacaine/height & $\begin{array}{l}\text { 24-gauge } \\
\text { Sprotte }\end{array}$ & $\begin{array}{l}\text { 25-gauge } \\
\text { Whitacre } \\
\left(\mathrm{mg} \cdot \mathrm{cm}^{-1}\right)\end{array}$ \\
\hline $0.05-0.06$ & $11 / 69)$ & $(n=150)$ \\
$0.06-0.07$ & $15 / 70$ & $2 / 65$ \\
$0.07-0.08$ & $0 / 11$ & $2 / 79$ \\
\hline
\end{tabular}

TABLE V Documented incidence of PDPH with the 24G Sprotte

\begin{tabular}{|c|c|c|c|c|}
\hline Author & Year & Study type & \multicolumn{2}{|c|}{ Incidence of PDPH } \\
\hline Sprotte $e t a l^{2}$ & 1987 & Prospective & $(0.02 \%)$ & \\
\hline Cesarini et al..$^{5}$ & 1990 & Prospective & $0 / 55$ & $(0 \%)$ \\
\hline Mayer et al. ${ }^{19}$ & 1991 & Prospective & $0 / 23$ & $(0 \%)$ \\
\hline Leeman ef al. ${ }^{3}$ & 1991 & Prospective & $2 / 55$ & $(3.6 \%)$ \\
\hline Ross et al. ${ }^{17}$ & 1992 & Retrospective & $2 / 132$ & (1.5\%) \\
\hline Devcic et al. ${ }^{4}$ & 1992 & Prospective & $4 / 71$ & $(5.6 \%)$ \\
\hline
\end{tabular}

with $3.3 \%(5 / 150)$ in the 25G Whitacre group $(P<$ 0.0001 ) (Table III). This was not related to position for insertion nor height of the block.

\section{Discussion}

The incidence of PDPH following the use of the 24G Sprotte spinal needle was first reported as $0.02 \%$ in an obstetrical population. ${ }^{2}$ This resulted in an increase in the use of spinal anaesthesia for parturients with a corresponding increase in the reported incidence of PDPH as high as $5.6 \%$ (Table V). Like the $24 \mathrm{G}$ Sprotte, the 25G Whitacre has a non-cutting, pencil point needle tip and might be expected to have a similar incidence of PDPH. 
Before initiating the study a power analysis was performed using a predicted incidence of PDPH with the 24G Sprotte of $4 \%$ (Leeman et al. ${ }^{3}$ ). To achieve a power of 0.80 , Type II statistical error of 0.20 , with an alpha of 0.05 , a total of 1239 patients in each group would have been required to demonstrate a $50 \%$ decrease (PDPH incidence 2\%) with the 25G Whitacre. This proved an unacceptably large number of patients in a tertiary care institution where approximately $1000 \mathrm{Cae}-$ sarean sections, elective and emergency, are done under spinal anaesthesia annually. Therefore, the authors chose 300 patients in which to compare the two needles within a reasonable time period.

Patients were questioned for five days to ensure all PDPH were detected. ${ }^{8}$ The $4 \%(6 / 150)$ incidence of PDPH found with the 24G Sprotte is consistent with the published results of Leeman et al. ${ }^{3}$ in 1991 and Devcic et al. ${ }^{4}$ in 1992. Interestingly, these results are higher than those reported by Sprotte et al. ${ }^{2}$ in 1987. Only one PDPH was observed with the $25 \mathrm{G}$ Whitacre needle for an incidence of $0.66 \%(1 / 150)$. This low incidence may be due to the $25 \mathrm{G}$ Whitacre needle's smaller size. A difference between the two needles might have been detected with a greater number of patients.

The incidence of non-spinal headache of $20.6 \%$ correlates with that reported following spontaneous vaginal delivery without either spinal or epidural anaesthesia: 22.3 to $25 \%{ }^{9}$ and $39 \% .^{10}$ This suggests that these non-spinal headaches were not related to spinal anaesthesia and more specifically not to the type of spinal needle.

A PDPH remains a frequent complication of spinal anaesthesia in the obstetrical population. It occurs most commonly in young, female patients (particularly parturients) $)^{11,12}$ and correlates with the size of the spinal needle used. ${ }^{13-15}$

There are many advantages of spinal over epidural anaesthesia for elective Caesarean section. The ease of the technique and the rapid onset of block decrease anaesthesia induction time. Major conduction blockade is provided with less chance of a patchy, unilateral or failed block: a problem that may occur with epidural anaesthesia. Spinal anaesthesia also exposes the parturient and fetus to a lower dose of local anaesthetic ${ }^{16}$ and narcotic. These advantages may be offset by a high incidence of PDPH which may lengthen hospital stay, require epidural autologous blood patch and interfere with the mother's care of her newborn.

The 24G Sprotte and 25G Whitacre needles are more expensive than Quincke spinal needles. One study ${ }^{17}$ found a higher incidence of PDPH with the 25G and 26G Quincke needles than with the 24G Sprotte needle (9\% with the $25 \mathrm{G}$ Quincke, $8 \%$ with the $26 \mathrm{G}$ Quincke vs $1.5 \%$ with the $24 \mathrm{G}$ Sprotte). Eight patients in the Quincke groups required autologous blood patch, compared with one in the Sprotte group. ${ }^{17}$ Mayer et al. ${ }^{19}$ reported a similar incidence of PDPH with the 27G Quincke needle and $24 \mathrm{G}$ sprotte needle. However, as they acknowledged, their study did not involve sufficient numbers to eliminate the possibility of Type II error. There is a slower return of CSF with the $27 \mathrm{G}$ Quincke, ${ }^{20}$ a disadvantage in a teaching hospital.

A need for epidural blood patch and additional hospitalization due to PDPH lead to additional cost, which could offset that of the Sprotte or Whitacre needles. Another possible cost is that resulting from litigation. Headache is the reason for $12 \%$ of obstetric malpractice claims in the United States with a median payment of $\$ 5,000.00$ (U.S.). ${ }^{18}$

At the time of this study the Sprotte needle was $\$ 2.00$ (Canadian) more expensive than the Whitacre needle. In 1992, 944 spinal anaesthetics were done at the Grace Hospital. Use of the Whitacre needle would have resulted in a saving of $\$ 1888.00$.

An incidental finding in our study was the increased incidence of intraoperative supplementation with the $24 \mathrm{G}$ Sprotte. It has been recommended that the Sprotte needle be advanced two or three milimeters once the subarachnoid space is entered to prevent this problem. ${ }^{6}$ Our data suggest that a larger dose of bupivacaine (i.e., $>0.07$ $\mathrm{mg} \cdot \mathrm{cm}^{-1}$ ) will also alleviate the need for intraoperative supplementation with the $24 \mathrm{G}$ Sprotte.

In conclusion, the results of this prospective, randomized double-blind study indicate that both the $24 \mathrm{G}$ Sprotte and the 24G Whitacre spinal needles are easy to use and deliver effective anaesthesia with a paucity of failed blocks and PDPH. As the Whitacre needle is less expensive than the Sprotte needle it is a reasonable alternative to the Sprotte needle for spinal anaesthesia for Caesarean section.

\section{Acknowledgements}

We thank Janet Lee Haines and Lois Obenauer for their assistance in the preparation of this manuscript. We acknowledge Becton Dickinson and Company, Rutherford, New Jersey for supplying the 25G Whitacre spinal needles used in this study.

\section{References}

1 Ready LB, Cuplin S, Haschke RH, Nessly M. Spinal needle determinents of rate of transdural fluid leak. Anesth Analg 1989; 69: 457-60.

2 Sprotte G, Schedel R, Pajunk H, Pajunk H. Eine "atraumtische" Universalkanule fur einzeitige Regional Anaesthesien. Reg Anesth 1987; 10: 104-8.

3 Leeman MI, Sears DH, O'Donnell LA, et al. The incidence of postdural puncture headache in obstetrical 
patients comparing the 24-gauge and 22-gauge Sprotte needles. Anesthesiology 1991; 75: A853.

4 Devcic C, Sprung J, Maitra- D'Cruze A, Haddox JD. Post-dural puncture headache in an obstetric population: comparison of 24-Ga Sprotte and 25-Ga Quincke needles. Reg Anesth (Supplement) 1992; 17: 69.

5 Cesarini $M$, Torrielli $R$, Lahaye F, Mene JM, Cabiro $C$. Sprotte needle for intrathecal anaesthesia for Caesarean section: incidence of postdural puncture headache. Anaesthesia 1990; 45: 656-8.

6 Crone $L A$, Vogel $W$. Failed spinal anesthesia with the Sprotte needle (Letter). Anesthesiology 1991; 75: 717-8.

7 Zar JH. Biostatistical Analysis. Englewood Cliffs, New Jersey: Prentice-Hall Inc., 1984, 2nd ed. 653-5.

8 Driessen A, Mauer W, Fricke M, Kossman B, Schleinzer $W$. Prospective studies on the pathologic mechanism of postspinal headache in a select group of patients. Anaesthetist 1980; 29: 38-41.

9 Grove $L H$. Backache, headache and bladder dysfunction after delivery. Br J Anaesth 1973; 45: 1147-9.

10 Stein G, Morton J, Marsh A, et al. Headaches after childbirth. Acta Neurol Scand 1984; 69: 74-9.

11 Vandam $L D$, Dripps RD Long-term follow-up of patients who received 10,098 spinal anesthetics: syndrome of decreased intracranial pressure (headache and ocular and auditory difficulties). JAMA 1956; 161: 586-91.

12 Brownridge P. Spinal anaesthesia revisited: an evaluation of subarachnoid block in obstetrics. Anaesth Intensive Care 1984; 12: 334-42.

13 Frumin MJ. Spinal anaesthesia using a 32-gauge needle. Anesthesiology 1969; 30: 599-603.

14 Tourtelote $W W$, Henderson WG, Tucker RP, Gilland $O$, Walker $J E$, Kokman E. A randomized, double-blind clinical trial comparing the 22 versus 26 gauge needle in the production of the post-lumbar puncture syndrome in normal individuals. Headache 1972; 12: 73-8.

15 Moore, $D C$. Factors influencing spinal anesthesia. Reg Anesth 1982; 7: 20-4.

16 Kuhnert BR, Zuspan KJ, Kuhnert PM, Syracuse CD, Brown $D E$. Bupivacaine disposition in mother, fetus, and neonate after spinal anesthesia for cesarean section. Anesth Analg 1987; 66: 407-12.

17 Ross BK, Chadwick HS, Mancuso JJ, Benedetti C. Sprotte needle for obstetric anesthesia: decreased incidence of post dural puncture headache. Reg Anesth 1992; 17: 29-33.

18 Chadwick HS, Posner K, Caplan RA, Ward RJ, Cheney $F W$. A comparison of obstetric and nonobstetric anesthesia malpractice claims. Anesthesiology 1991; 74: 242-9.

19 Mayer $D C$, Quance D, Weeks $S K$. Headache after spinal anesthesia for cesarean section: a comparison of the 27gauge Quincke and 24-gauge Sprotte needles. Anesth Analg 1992; 75: 377-80.
20 Zucker-Pinchoff B, Ruttenberg $M$. A comparison of spinal needle flow rates. Reg Anesth (Supplement) 1993; 18 : 86. 